\title{
A ESTADUALIZAÇÃO DO PROGRAMA CULTURA VIVA
}

\author{
Sophia Cardoso Rocha ${ }^{1}$
}

Resumo: O Ministério da Cultura (MinC) vem empreendendo esforços para fortalecer o pacto federativo brasileiro por meio da descentralização de suas políticas. Nesse sentido, este artigo analisa a experiência de estadualização do Programa Cultura Viva/Projeto Ponto de Cultura no Estado da Bahia. Tal estudo revela que o MinC adotou, como modelo de descentralização, a reprodução de programas e projetos de sua própria autoria; verifica que o Programa Cultura Viva, ainda que marcado por uma série de problemas, foi o principal eixo de ação do Programa Mais Cultura, que promoveu a sua expansão; aponta que a estadualização do Projeto Ponto de Cultura não resolveu as dificuldades enfrentadas em âmbito federal, e sim as replicou; e por fim, destaca questões a serem discutidas na perspectiva da consolidação do Sistema Nacional de Cultura (SNC).

Palavras-Chave: Pacto federativo. Descentralização. Políticas culturais. Programa Cultura Viva.

Abstract: Brazil's Ministry of Culture (MinC) has made efforts to decentralize cultural policies in order to strengthen what is called Federative Pact, that is, the articulation between central state, local states and municipalities. Accordingly, this article examines the experience of decentralization of the "Cultura Viva" Program and its specific project denominated "Ponto de Cultura" in the Bahia State. The article suggests the following: the MinC has adopted a top-down approach whereby it central policies have been developed centrally and implemented locally; even though marked by a series of problems, the "Cultura Viva" was the main axis of action of the "Mais Cultura" Program, which promoted its expansion; the decentralization of the "Ponto de Cultura" Project has exacerbated rather than solving the difficulties facing the Federative Pact with regard to the National System of Culture.

Keywords: Federative pact. Decentralization. Cultural policies. "Cultura Viva” Program.

\footnotetext{
${ }^{1}$ Doutoranda do Programa Multidisciplinar em Cultura e Sociedade da Universidade Federal da Bahia. Bolsista da Capes. e-mail: sophiacrocha@gmail.com.
} 


\section{Introdução}

Em 2014, o Programa Cultura Viva completa dez anos de existência. A publicação da Lei nº. 13.018/2014, que institui a Política Nacional de Cultura Viva, enseja um momento especial de reflexão sobre a sua trajetória. Uma das possíveis perspectivas de análise refere-se aos impactos de sua descentralização, realizada por meio de parcerias com Estados e municípios. Nesse sentido, este artigo se propõe a analisar a estadualização do projeto "Ponto de Cultura" no Estado da Bahia.

Como esse texto trata da descentralização do Cultura Viva, consideramos imprescindível dialogar com outro Programa do MinC, denominado Mais Cultura. Avaliado por alguns como o "embrião" do SNC, o Mais Cultura teve um papel fundamental na articulação dos entes federados para a implantação de uma série de projetos culturais, tais como o Ponto de Cultura.

Nesse sentido, a hipótese apresentada neste artigo, em resumo, é que a estadualização do Projeto Ponto de Cultura contribuiu para a sua expansão - tanto em relação à quantidade de projetos, como em sua distribuição territorial. Porém, os problemas diagnosticados no Projeto, quando era gerido exclusivamente pelo MinC, continuaram a ocorrer após a sua descentralização, multiplicando-se para Estados e municípios, ainda que estes se empenhassem em qualificar a sua gestão. Isso nos indicaria que os entraves vivenciados no Ponto de Cultura refletem um problema mais profundo, que é a inadequação do modelo de Estado existente no Brasil, incapaz de dialogar com todo o conjunto de sua população.

Ressaltamos, por fim, que este artigo teve como procedimento metodológico a análise documental, feita a partir de fontes secundárias; e que o seu referencial teórico foi constituído de textos publicados sobre o tema e assuntos correlatos.

\section{O Programa Mais Cultura}

O ano de 2007 é fundamental para compreender o processo de expansão do projeto Ponto de Cultura para Estados e municípios brasileiros. A descentralização ocorreu, sobretudo, por meio do Programa Mais Cultura, que integrava o Programa de Aceleração do Crescimento (PAC) instituído pelo governo federal neste mesmo ano.

Com a expectativa de alterar o rumo da política econômica em curso até aquele momento (CARVALHO; LEPKSON, 2007), o PAC pretendia estimular o setor produtivo da economia 
Políticas Culturais em Revista, 2(7), p. 26-45, 2014 - www.politicasculturaisemrevista.ufba.br

brasileira, impulsionar a modernização tecnológica, acelerar o crescimento, ampliar a competitividade e integrar o Brasil a outras partes do mundo (BRASIL, 2010). Além disso, a Agenda Social do governo propunha consolidar a garantia dos direitos, reduzir a desigualdade social e fortalecer o pacto federativo. Foi nesse âmbito que a Cultura integrou o PAC, com a criação do Programa Mais Cultura, cujo slogan era "Promover o acesso à cultura e à diversidade é investir em um país de todos". De acordo com o então ministro Gilberto Gil (2007), o ingresso do Programa Mais Cultura na Agenda Social colocava a cultura em um novo patamar, reconhecendo-a, não apenas como responsabilidade do MinC, mas do próprio governo.

Um dos aspectos fundamentais neste Programa era a impulsão do diálogo do MinC com outros órgãos. De acordo com Decreto n. ${ }^{\circ}$ 6.226/2007, a execução do Mais Cultura se daria mediante acordos com órgãos e entidades da administração pública federal, dos Estados e municípios, dentre outras instituições. Nesse sentido, observa-se que havia expressamente o intuito de fortalecer o pacto federativo. Foi pela proposta de estabelecer parcerias com os entes federados, para repassar recursos e implantar processos de estadualização de programas e políticas, que o Mais Cultura foi considerado como um passo inicial na construção do Sistema Nacional de Cultura (CALABRE, 2014), ainda que "à medida que as ações e subprogramas que compunham o Mais Cultura desenrolavam-se, mais claras ficavam as contradições entre o sistema e o programa que lhe serviria como exemplo e base empírica" (SILVA, 2011, p. 11).

Para compreender melhor como o Programa se desenvolveu, é preciso esclarecer que ele estava alinhado às diretrizes do PAC, que estabeleceu um conjunto de áreas prioritárias. Assim, o MinC pretendia atender: áreas de conflitos e disputas territoriais; periferias e áreas de precariedade habitacional; reservas indígenas; comunidades remanescentes dos quilombos; municípios com os maiores índices de violência no país; municípios com os menores Índices de Desenvolvimento da Educação Básica; e territórios rurais e de cidadania. Isso significa que o Programa deveria atingir uma grande e esparsa área do território nacional; e beneficiar grupos sociais dos mais variados perfis.

Para atender aos seus objetivos de "I - ampliar o acesso aos bens e serviços culturais e meios necessários para a expressão simbólica [...]; II - qualificar o ambiente social das cidades e do meio rural [...]; e III - gerar oportunidades de trabalho, emprego e renda [...]”. (BRASIL, 2007, p. 1), o Programa se estruturou sobre eixos, diretrizes e linhas de ações (Quadro 1). 
Políticas Culturais em Revista, 2(7), p. 26-45, 2014 - www.politicasculturaisemrevista.ufba.br

\begin{tabular}{|c|c|c|c|}
\hline & I: Cultura e Cidadania & II - Cultura e Cidades & III - Cultura e Economia \\
\hline Diretrizes & $\begin{array}{l}\text { - Promover melhoria da } \\
\text { qualidade de vida; } \\
\text { - Valorizar e fortalecer a } \\
\text { diversidade cultural; } \\
\text { - Ampliar o acesso aos } \\
\text { bens e serviços culturais }\end{array}$ & $\begin{array}{l}\text { - Qualificar o ambiente } \\
\text { social das cidades por } \\
\text { meio da construção, } \\
\text { reforma, modernização e } \\
\text { adaptação de espaços } \\
\text { culturais; } \\
\text { - Democratizar o acesso a } \\
\text { equipamentos culturais e } \\
\text { atrair, principalmente, as } \\
\text { populações de áreas } \\
\text { menos favorecidas. }\end{array}$ & $\begin{array}{l}\text { - Gerar oportunidades de } \\
\text { emprego e renda para } \\
\text { trabalhadores, micro, pequenas } \\
\text { e médias empresas do mercado } \\
\text { cultural brasileiro; } \\
\text { - Incorporar progressivamente a } \\
\text { parcela informal de } \\
\text { trabalhadores da cultura na } \\
\text { economia formal; } \\
\text { - Disponibilizar acesso a } \\
\text { créditos e meios de circulação } \\
\text { e veiculação de bens e serviços } \\
\text { culturais. }\end{array}$ \\
\hline Ações & $\begin{array}{l}\text { - Pontos de Cultura } \\
\text { - Pontos de Leitura } \\
\text { - Pontinhos de Cultura } \\
\text { - Cine Mais Cultura } \\
\text { - Produção de conteúdos } \\
\text { para TV Pública } \\
\text { - Agente de Leitura } \\
\text { - Vale Cultura } \\
\text { - Periódicos de conteúdo } \\
\text { Mais Cultura }\end{array}$ & $\begin{array}{l}\text { - Bibliotecas } \\
\text { - Espaços Mais Cultura } \\
\text { - Pontos de Memória }\end{array}$ & $\begin{array}{l}\text { - Promoção do Artesanato de } \\
\text { Tradição Cultural (Promoart) } \\
\text { - Microcrédito Cultural } \\
\text { - Microprojetos Mais Cultura }\end{array}$ \\
\hline
\end{tabular}

Quadro 1 - Diretrizes e Ações do Mais Cultura

Fonte: Elaboração própria, a partir de informações do MinC.

Sobre a implantação dessas ações é preciso registrar duas coisas. A primeira é que se deu a partir de parcerias, sobretudo com governos estaduais, ou seja, dependia da atuação de outro agente político para ser executada. De acordo com o ex-ministro Juca Ferreira (2008, p.1): "Queremos envolver todos os governos estaduais nesse programa, de forma republicana. $\mathrm{O}$ Brasil tem condições de melhorar seus investimentos e faremos isso de forma compartilhada". A segunda é que tais ações, em sua maioria, já existiam antes da criação do Mais Cultura, ou seja, ele incorporava projetos e programas já criados pelo Ministério, a exemplo do Ponto de Cultura.

O Mais Cultura era um programa ambicioso, reconheça-se. Tentou, com graus discutíveis de sucesso, reorganizar vários projetos que já estavam em andamento - alguns de média duração - e criou alguns novos, dando-lhes, no plano das justificativas e organizações conceituais, uma estrutura coerente com algumas das grandes preocupações do então governo: combate às desigualdades, redistribuição de recursos para os municípios mais pobres, reinvenção do pacto republicano, reinvenção do Estado, ênfase na participação popular etc. (SILVA, 2011, p. 9)

A execução de programas e projetos já instituídos exigia uma grande articulação interna por parte do MinC, uma vez que o Mais Cultura era coordenado pela Secretaria de Articulação 
Políticas Culturais em Revista, 2(7), p. 26-45, 2014 - www.politicasculturaisemrevista.ufba.br

Institucional, ao passo que a maioria do seus projetos integravam outras secretarias, como a Secretaria de Cidadania Cultural ${ }^{2}$ (SCC), no caso dos Cultura Viva. A sobreposição de programas e projetos administrados por secretarias distintas buscou reestruturar e melhorar a aplicação de recursos, porém levou a disputas internas e entraves nos processos decisórios no âmbito do próprio Ministério (LIMA, 2012).

O Programa, portanto, possuía um cenário peculiar: tinha como principal foco projetos que não foram criados na sua estrutura, e que já possuíam trajetórias marcantes, como o Cultura Viva; envolvia expressiva diversidade temática, de público beneficiado e de área geográfica a ser atingida; e buscava ser implementado a partir de convênios firmados com outros entes federados, o que implicava ampliar territorialmente as suas ações, mas, também, enfrentar difíceis questões políticas.

No aspecto relativo à promoção de ações descentralizadas e ao fortalecimento do pacto federativo, é preciso questionar se a maneira de implementar os projetos - previamente elaborados, formatados e estruturados pelo Ministério - fortalecia a relação União-EstadosMunicípios ou se era uma estratégia para expandir a centralidade do MinC, que replicava assim as suas ideias e propostas de ação, sem delegar aos demais entes poder decisório; a esses cabia aceitar ou não o ingresso no Mais Cultura. Isso por que, para alguns autores, descentralização se relaciona com distribuição territorial do poder e implica a delegação de autoridade legal e política aos poderes locais (JACOBI, 2000). De acordo com Marta Arrecthe, dado o contexto histórico brasileiro, pós-ditadura, a descentralização passou a ser sinônimo de democracia, ao passo que a centralização passou a ser associada à impossibilidade de controle social, à falta de transparência nas decisões, enfim, a práticas nãodemocráticas de decisão. Entretanto,

[...] não existe uma garantia prévia - intrínseca ao mecanismo da descentralização de que o deslocamento desses recursos implique a abolição da dominação. Deslocar recursos do 'centro' para subsistemas mais autônomos pode evitar a dominação pelo 'centro', mas pode permitir essa dominação ao interior desse subsistema. (1996, p. 6)

Além disso, o fortalecimento do poder central em políticas descentralizadas nem sempre é um equívoco, mesmo porque o sucesso dessas políticas provoca uma nova estratégia de ação, por parte do governo federal, exigindo "o fortalecimento de suas capacidades administrativas e institucionais na condução e regulação de políticas setoriais implementadas pelos governos subnacionais e do próprio processo de descentralização" (ARRETCHE, 1996, p. 22). Segundo

\footnotetext{
${ }^{2}$ Atual Secretaria da Cidadania e da Diversidade Cultural (SCDC).
} 
Políticas Culturais em Revista, 2(7), p. 26-45, 2014 - www.politicasculturaisemrevista.ufba.br

a autora, em países como o Brasil, onde as disparidades intrarregionais são significativas, torna-se ainda mais importante o papel do poder central.

Apesar de todas essas dificuldades e desafios, a experiência do Mais Cultura pode ser considerada como positiva, sobretudo por ter inserido a área da cultura no rol de prioridades do governo. De acordo com o "Balanço do Governo para área da Cultura" (2003-2010), o Programa implantou 1.610 bibliotecas municipais (outras 1.774 foram modernizadas), 821 Cines Mais Cultura, 1.393 Pontos de Leitura e cerca de quatro mil Pontos de Cultura. ${ }^{3}$ Mais de 135 acordos de cooperação foram assinados. Vale destacar que o Programa chegou a absorver, em 2009, 67\% dos recursos do Fundo Nacional de Cultura (SILVA, 2011), ou seja, era um Programa fundamental para o Ministério.

\section{A descentralização do Cultura Viva}

Foi relatado anteriormente que o Programa Mais Cultura estava sustentado, em grande parte, em programas e projetos já existentes. Isso teria sido um dos motivos que contribuiu para a sua pouca visibilidade (CALABRE, 2010). O Cultura Viva, sem dúvida, era um desses programas que possuía grande destaque e que foi bastante beneficiado pelo Mais Cultura, como demonstra o Quadro 2. Mas quais teriam sido os motivos para tal escolha? Poderíamos pensar, pelo menos, em três perspectivas: (1) potencialidade de gerar impacto local, envolvendo diversos grupos culturais; (2) experiência na articulação de outros programas do Ministério, a exemplo do livro e da leitura; e (3) reconhecimento da sociedade civil e de órgãos públicos (governos estaduais, municipais e órgãos da União). Tudo isso, certamente, reduziria o risco de resistência para a descentralização da política do Ministério.

\begin{tabular}{|c|c|c|c|}
\hline Cultura Viva & Limite liberado (R\$) & Executado (R\$) & $\begin{array}{c}\text { Resultados Alcançados } \\
\text { (No de Pontos de Cultura) }\end{array}$ \\
\hline $\mathbf{2 0 0 4}$ & 4.073 .738 & 4.073 .733 & 72 \\
\hline $\mathbf{2 0 0 5}$ & 53.854 .365 & 53.822 .384 & 642 \\
\hline $\mathbf{2 0 0 6}$ & 45.621 .413 & 45.621 .413 & 742 \\
\hline $\mathbf{2 0 0 7}$ & 127.333 .929 & 126.550 .088 & 2.446 \\
\hline $\mathbf{2 0 0 8}$ & 120.600 .000 & 119.713 .542 & \\
\hline
\end{tabular}

${ }^{3}$ Esse dado diverge de outros disponibilizados no site do MinC. Consulta recente revela que de 2004 a 2013 havia 3.663 Pontos. Disponível em: <http://www.cultura.gov.br/pontos-de-cultura1>. Acesso em: 10 nov. 2014. 
Políticas Culturais em Revista, 2(7), p. 26-45, 2014 - www.politicasculturaisemrevista.ufba.br

\begin{tabular}{|l|l|l|l|}
\hline $\mathbf{2 0 0 9}$ & 120.080 .500 & 119.547 .737 & 2.517 \\
\hline
\end{tabular}

Quadro 2 - Resumo do investimento no Programa Cultura Viva

Fonte: Elaborado a partir de dados da Controladoria Geral da União.

Com o Mais Cultura, além do incremento orçamentário, o Projeto Ponto de Cultura alcançou expressiva ampliação territorial devido à participação, sobretudo de Estados, ${ }^{4}$ que passaram a publicar editais.

De maneira geral, o Projeto continuava o mesmo: cada Ponto de Cultura recebia, ao longo de três anos, 180 mil reais para fomentar ações que já desenvolviam em sua comunidade. Ainda assim, houve mudanças importantes no Projeto após a sua descentralização. Uma delas foi que, com o ingresso dos governos estaduais, os Pontos de Cultura não precisaram mais aportar a contrapartida, exigida quando o convênio é firmado diretamente com o MinC. ${ }^{5}$ Isso porque os Estados passaram a financiar 1/3 do valor do Projeto, assumindo tal contrapartida e isentando os Pontos de desembolsarem esse recurso.

Além do repasse anual da verba aos Pontos, cabia aos Estados promover assistência técnica, desenvolver atividades de integração e acompanhar os projetos (BRASIL, 2007). Ou seja, com a descentralização, secretarias estaduais e municipais de cultura passaram a assumir o papel de gestores da rede de Pontos de Cultura.

Assumir tal papel implicou na difícil tarefa de administrar um projeto com inúmeros entraves, como já foi apontado em estudos e pesquisas. De acordo com Célio Turino (2009), exsecretário da SCC, o programa enfrentou diversos problemas, tais como: burocratismo no processo de conveniamento, atraso no repasse de verba, normas em desacordo com a realidade dos Pontos, prestação de contas imperfeitas etc.

Se para o MinC a descentralização possibilitou a redução desses enfrentamentos - pois deixaram de firmar convênio diretamente com os Pontos -, Estados e municípios passaram a assumir esse lugar, reproduzindo e multiplicando as dificuldades já enfrentadas pelo órgão federal.

Nesse sentido, a expansão do Cultura Viva revela um paradoxo interessante. Ao mesmo tempo em que foi um programa que enfrentou muitos entraves, foi foco de grande

\footnotetext{
${ }^{4}$ Atualmente, o Projeto envolve 25 Estados, Distrito Federal e, apenas 56 municípios. Disponível em: $<$ http://www.cultura.gov.br/pontos-de-cultura1 $>$. Acesso em: 17 nov. 2014.

5 Essa exigência deve-se ao fato da fonte de financiamento do Projeto ser o Fundo Nacional de Cultura, que estipula que a União deve financiar até $80 \%$ do valor do projeto, e que os $20 \%$ restantes devem ser contrapartida.
} 
investimento por parte do MinC. Acrescente-se a esse complexo cenário o ingresso de novos atores (entes federados) por meio do Mais Cultura.

[...] quando uma política envolve diferentes níveis de governo - federal, estadual, municipal - ou diferentes regiões de um mesmo país, ou ainda, diferentes setores de atividade [...] quando a ação depende de um certo número de elos numa cadeia de implementação, então o grau necessário de cooperação entre as organizações para que esta cadeia funcione pode ser muito elevado. (RUA, 1998, p. 13-14)

Tal cooperação apresentava algumas resistências, já que a descentralização do Cultura Viva era visto com desconfiança por parte de alguns Pontos de Cultura. De acordo com a pesquisa do Ipea (2010, p. 33):

A despeito do reconhecimento [por parte dos Pontos] da necessidade de articulação com as secretarias estaduais e municipais, há um grande temor do que se refere às ingerências político-partidárias, o que denota ceticismo quanto ao processo de descentralização dos editais ou municipalidades. Além disso, a atual capacidade do MinC de acompanhamento, avaliação e descentralização é vista como insuficiente para garantir autonomia, transparência e participação.

Por outro lado, para o Programa se expandir, o Ministério reconhecia que era preciso descentralizá-lo. De acordo com Célio Turino (2009, p. 167), quando da avaliação do ingresso do Mais Cultura no Projeto Ponto de Cultura:

Há muitas vantagens nesse processo: o primeiro é o fato de o Ponto de Cultura tornar-se política de Estado, realizada pelos diversos entes federados, independente de conveniências ou disputa entre governos e partidos [...]. Pode haver problemas como a tentação da manipulação ou perseguição política [...] e o risco de burocratismo local também existe? Sim. Mas a garantia de que isto não aconteça está exatamente no empoderamento da rede de Pontos que já existe, na apropriação do conceito por parte da sociedade, no pacto federativo e na vigilância do governo federal.

De fato, se o MinC já apresentava dificuldades em promover a gestão do Cultura Viva, quando a sua rede possuía cerca de 600 Pontos de Cultura, seria improvável imaginá-lo administrando mais de 2.500 projetos. Nesse sentido, a estadualização foi fundamental para a expansão do Programa.

\section{A experiência da estadualização do Projeto Ponto de Cultura na Bahia}

A partir de meados dos anos 2000, o Ministério da Cultura e a Secretaria Estadual de Cultura da Bahia (Secult) firmaram diversas parcerias. Os programas e projetos federais implantados 
Políticas Culturais em Revista, 2(7), p. 26-45, 2014 - www.politicasculturaisemrevista.ufba.br

no Estado buscavam, por sua vez, atender à sua política de territorialização que, em resumo, pretendia diminuir a disparidade entre capital e interior e atender a regiões de Salvador que estavam alijadas do alcance do governo estadual (RUBIM, 2014). Para tanto, utilizou-se o conceito de territórios de identidade.

[...] Em 2007, o governo reconheceu a existência de 26 Territórios de Identidade [...], que foram cunhados por arranjos sociais e locais. A adoção da nova territorialização teve como justificativa o desenvolvimento de todas as regiões da Bahia, através da atuação governamental de acordo com as características locais e as necessidades de cada território. (CANEDO, 2008, p. 73)

Essa política explica a imposição de determinados critérios em editais derivados do Programa Mais Cultura, cujo acordo de cooperação foi firmado em 2007. Nesse sentido, os editais publicados pela Secult estabeleciam, sempre que possível, um sistema de cotas por território de identidade, no intuito de possibilitar uma distribuição mais equitativa dos investimentos. O Edital Pontos de Cultura foi um desses casos.

\section{$\underline{\text { O Edital Pontos de Cultura da Bahia }}{ }^{6}$}

O convênio $n^{\circ} 427 / 2007$, firmado entre o MinC e a Secult, para implantação da rede estadual de Pontos de Cultura na Bahia, previu a publicação de edital de seleção de 150 instituições da sociedade civil sem fins lucrativos para receberem apoio no valor de 60 mil reais por ano, durante três anos consecutivos, no total de 180 mil reais por projeto.

De acordo com esse convênio, o edital seguiria modelo disponibilizado pelo MinC, mas, na prática, houve alterações. Inicialmente, pela necessidade de reajustes para atender às exigências legais da União e do Estado. E depois, pelo fato da Secult instituir como critério de seleção a distribuição de cotas de projetos por territórios de identidade, ${ }^{7}$ conforme gráfico a seguir.

\footnotetext{
${ }^{6}$ Em 2014, foi publicado novo edital selecionando 128 instituições. Como elas ainda não firmaram convênio com a Secult e, portanto, não integram oficialmente a Rede de Pontos, este artigo optou por desconsiderá-las.

${ }^{7}$ Considerando a proporção entre quantidade de habitantes e de municípios de cada território.
} 


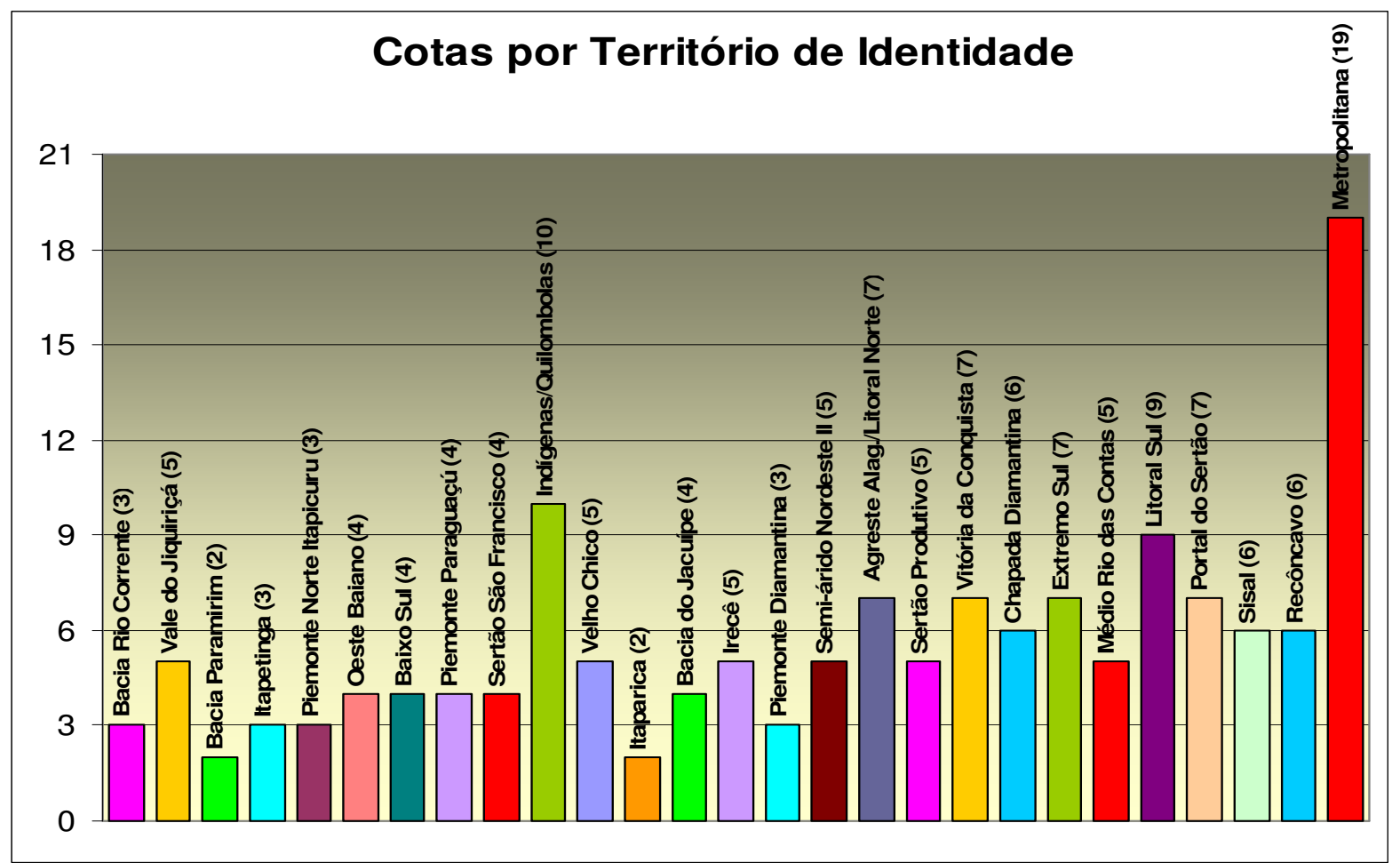

Gráfico 1 - Distribuição das cotas de Pontos de Cultura por Território de Identidade Fonte: Superintendência de Cultura/Secretaria de Cultura da Bahia.

A proposta da Secult era evitar a concentração de Pontos, já que caso o critério de seleção fosse exclusivamente qualidade técnica, as instituições mais estruturadas, com maior tradição em elaboração de projetos e captação de recursos, seriam as principais beneficiadas. E estas se localizavam, em grande parte, em Salvador e nas regiões mais desenvolvidas do Estado. Essa preocupação foi fundada, também, na experiência do Ministério, visto que 50,9\% dos seus Pontos de Cultura da Bahia estavam localizados na capital do Estado. Sem a instituição de cotas por parte da Secult, essa situação poderia se repetir.

Nesse sentido, o objetivo da Secretaria foi alcançado. Dos 394 projetos inscritos na seleção, 117 estavam na Região Metropolitana de Salvador, quase 30\%. Esse percentual, seguindo critério do edital, deveria ser reduzido para $12,6 \%$. No resultado final, esse percentual foi de 18,6\% (ROCHA, 2011).

Nos mapas a seguir é possível observar como ficou a distribuição territorial dos Pontos conveniados com o MinC (Mapa 1), aproximadamente 70, e com a Secult (Mapa 2), 150. 
Políticas Culturais em Revista, 2(7), p. 26-45, 2014 - www.politicasculturaisemrevista.ufba.br

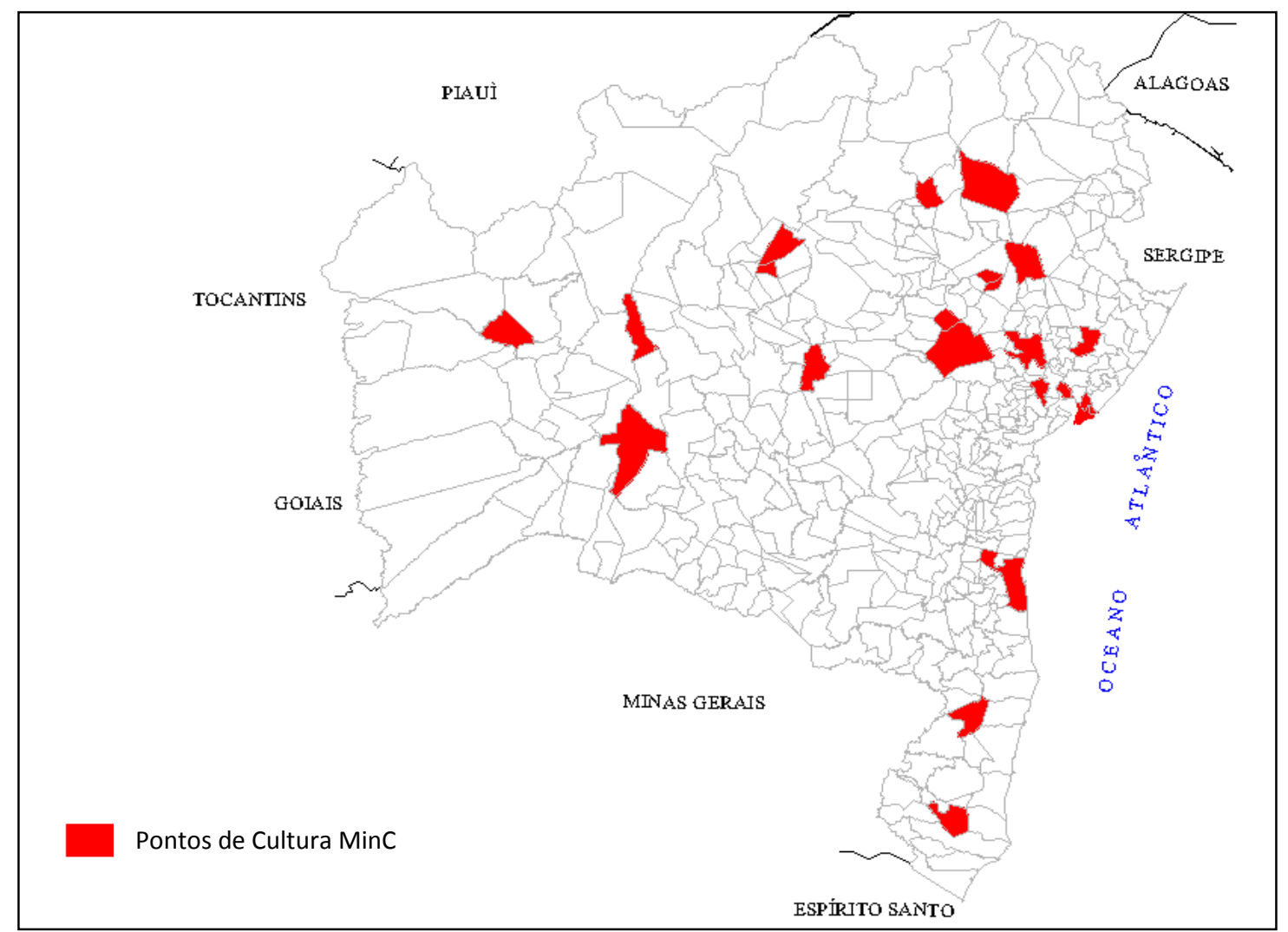

Mapa 1 - Distribuição dos Pontos de Cultura conveniados com o MinC

Fonte: Elaboração própria, a partir de dados do Setor de Gestão de Informações do Ponto da Secretaria de Cidadania Cultura/MinC.

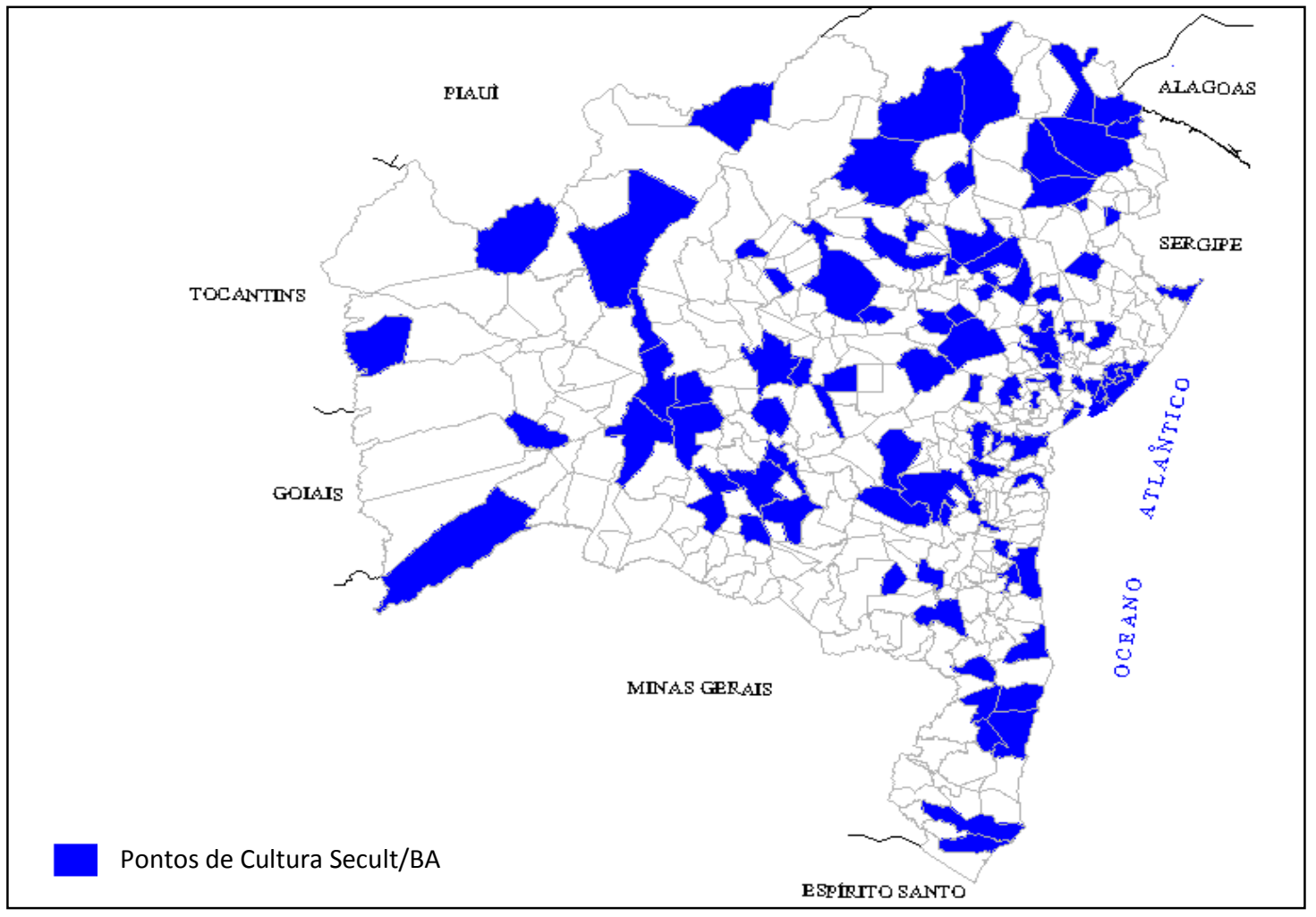

Mapa 2 - Distribuição dos Pontos de Cultura conveniados com a Secult

Fonte: Elaboração própria, a partir de dados da Superintendência de Cultura/Secult. 
Políticas Culturais em Revista, 2(7), p. 26-45, 2014 - www.politicasculturaisemrevista.ufba.br

\section{A gestão do Projeto Ponto de Cultura na Secult}

O início da gestão do Projeto na Secretaria foi marcado pela necessidade de encontrar caminhos que se adequassem tanto às exigências da União, quanto às do Estado. Esse processo, ainda que lento, produziu alguns efeitos positivos, um deles foi a dispensa de licitação para a aquisição de equipamentos por parte dos Pontos de Cultura da Bahia, conforme parecer da Procuradoria Geral do Estado (BAHIA, 2008).

Outro aspecto interessante foi o modelo planejado pela Secult para acompanhar os projetos. Além de uma Coordenação central, sediada em Salvador, na Superintendência de Desenvolvimento Territorial da Cultura (Sudecult), o Projeto fazia parte das atividades dos representantes territoriais, funcionários da Secretaria que trabalhavam nos territórios. Por meio do trabalho dos representantes pretendia-se, por exemplo, melhorar a comunicação entre as entidades e a Secult, um dos aspectos mais criticados pelos Pontos conveniados com o MinC (IPEA, 2010).

Apesar do papel estratégico dos representantes territoriais para o Projeto, a sua participação sofreu diversos reveses. Como esses funcionários atendiam a todos os assuntos da Secretaria, a Coordenação dos Pontos precisava disputar a sua agenda com outros setores da própria Secult. Além disso, para cada território de identidade, só havia um representante (exceto a RMS, que contava com dois), ou seja, considerando a dimensão da Bahia e a quantidade de municípios em cada território, era difícil percorrer todas as localidades com a frequência ideal. Esses funcionários, inclusive, não possuíam uma estrutura adequada de trabalho, o que dificultava a comunicação entre eles e o Ponto. Além disso, houve períodos em que alguns territórios ficaram sem representantes. Ainda com todas essas dificuldades, ocorreram algumas visitas aos Pontos, na maior parte, de caráter fiscalizador (averiguar a instalação de equipamentos, visibilidade do espaço para a comunidade do entorno, a organização de documentos etc.), o que favoreceu o trabalho de acompanhamento por parte da Coordenação.

A estadualização promoveu, também, impactos interessantes em relação ao fomento de novas ações que buscavam fortalecer o Projeto. Podemos citar, por exemplo, o Programa Jovens Multiplicadores de Cultura, parceria Secult - Casa Civil/Fundo Estadual de Combate e Erradicação da Pobreza, cujo objetivo principal era estimular a participação de jovens em atividades culturais dentro dos Pontos de Cultura. O Edital, publicado em 2011, previu uma bolsa mensal no valor de 250 reais e tinha como meta selecionar até 440 jovens para atuar como multiplicadores de cultura em áreas de vulnerabilidade social. Para participar, cada 
Políticas Culturais em Revista, 2(7), p. 26-45, 2014 - www.politicasculturaisemrevista.ufba.br

Ponto de Cultura precisava enviar um projeto envolvendo, no máximo, quatro jovens. Como resultado do edital, obteve-se a seleção de 48 Pontos e de 128 jovens, aquém do esperado.

De acordo com a avaliação produzida pela Secult ao final do programa, em agosto de 2014, dos 128 jovens que ingressaram apenas 47 permaneceram até a sua conclusão. A evasão teria ocorrido por vários motivos, dentre eles a necessidade dos jovens buscarem melhor remuneração. Além disso, foram registrados repetidos atrasos no pagamento das bolsas, devido a problemas no sistema bancário. Ainda assim, a experiência foi avaliada como positiva.

\begin{abstract}
Além de beneficiar os jovens e suas famílias, o Programa também beneficiou as comunidades. O papel de multiplicador assumido pelo jovem fez com que ele repassasse o conhecimento adquirido para outras pessoas da comunidade e movimentasse a cultura local. Manter os jovens nas atividades dos Pontos de Cultura também foi uma forma de minimizar as condições de vulnerabilidade. (BAHIA/SECULT, 2014, p. 10).
\end{abstract}

No gráfico a seguir é possível observar os impactos produzidos pelo programa, na visão dos jovens.
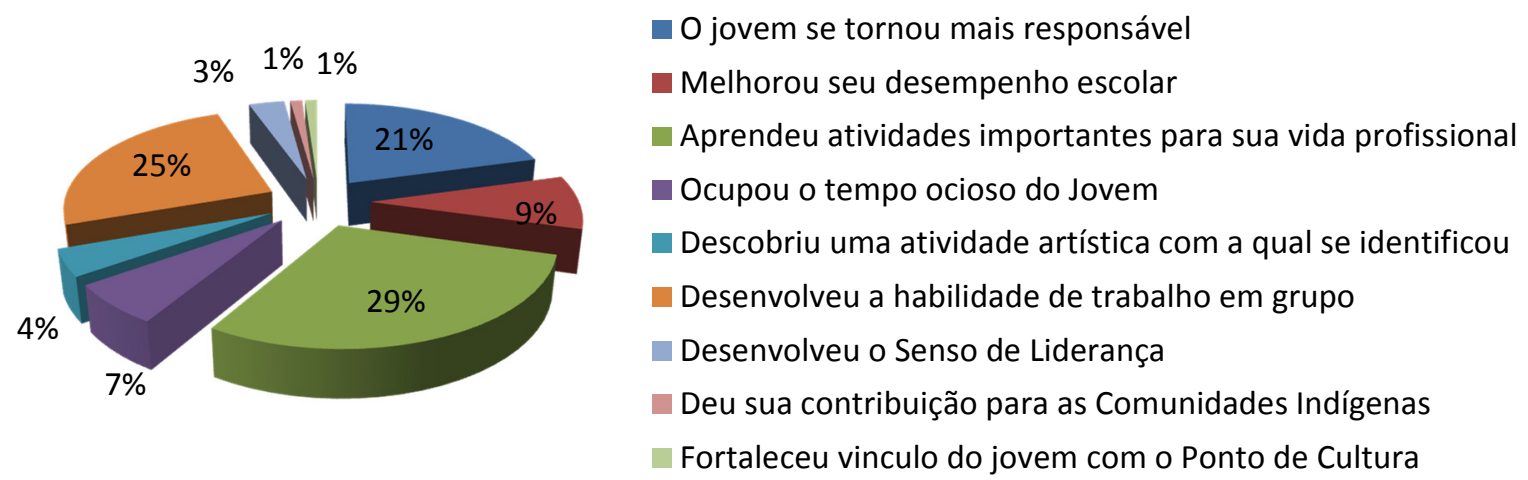

Gráfico 2 - De que forma o Programa contribuiu para a formação do jovem? Fonte: Sudecult/Secult.

Observa-se, também, que, com a estadualização, a Secult promoveu e apoiou a realização de eventos, encontros e atividades de formação. Tais encontros buscavam sempre integrar toda a Rede de Pontos de Cultura da Bahia - composta por cerca de 200 entidades, contando aquelas conveniadas com a Secult e com o MinC. De 2008 a 2014, a Secult promoveu duas Teias estaduais (2009 e 2014) e participou de três Teias nacionais (2008, 2010 e 2014). Ao mesmo tempo, os próprios Pontos promoveram encontros territoriais, a exemplo do encontro dos Pontos do Litoral Sul, de Vitória da Conquista e do Sisal. Em relação às atividades de formação, ora dirigidas especificamente para os Pontos, ora integrando-os a outras redes, é 
Políticas Culturais em Revista, 2(7), p. 26-45, 2014 - www.politicasculturaisemrevista.ufba.br

possível citar a Oficina de Formação em Gestão Cultural (2009), em parceria com o Pontão de Cultura Comunidade Santo Antônio/MG; Oficina de Cultura Digital em Software Livre (2009); Oficina de Produção Cultural e Oficina de Audiovisual (2013); e Oficina de Formação em Gestão dos Pontos de Cultura (2014), em parceria com o Escritório Bahia Criativa. Por fim, houve, também, as publicações do Catálogo dos Pontos de Cultura (2011), com informações sobre cada projeto e, também, do Manual de Prestação de Contas.

Se a Secretaria avançou em alguns critérios, outros precisariam ser revistos. Um ponto crítico na gestão desse Projeto foi a demora em desenvolver um sistema informatizado de acompanhamento. De acordo com o convênio no 427/07, o Ministério deveria:

Definir o conjunto de informações qualitativas e quantitativas sobre as atividades desenvolvidas pelos Pontos de Cultura no âmbito dos projetos apoiados, produção realizada e público-alvo atendido a ser armazenado em banco de dados pelos Estados e periodicamente atualizado. (BRASIL, 2007, p.3)

Passados sete anos, o MinC não disponibilizou nenhum modelo de sistema para os Estados. Isso impactou, não apenas no acompanhamento cotidiano dos projetos, mas também a realização de estudos, pesquisas e avaliações. Nesse sentido, a Secult iniciou em 2014, por conta própria, a implantação de um sistema, que se encontra em fase de teste.

Outro problema, certamente o mais crítico de todos, refere-se ao andamento dos convênios assinados com os Pontos. Da mesma maneira que ocorria quando o convênio era firmado com o MinC, as entidades vêm enfrentando grandes dificuldades para executar o projeto. A maior parte, por exemplo, não consegue cumprir o plano de trabalho aprovado, requerendo inúmeras alterações que precisam ser aprovadas pela Secult, o que demanda tempo; há ações executadas de maneira inadequada, como a aplicação de verba para capital em despesas do tipo custeio, ou a utilização de parte do rendimento em gastos não permitidos por Lei. Tudo isso repercute em atrasos na execução do projeto, na entrega de prestações de contas e na possibilidade da aprovação destas por parte da Secretaria. Esta, por outro lado, não possui equipe de trabalho suficiente para absorver as demandas dos Pontos, ainda que tenha ampliado o número de funcionários e reorganizado melhor a sua equipe. Para completar esse cenário, há contingenciamento de recursos por parte do Estado e da União, o que impede o repasse dos recursos aos Pontos.

Para se ter uma ideia da situação atual, dos 149 Pontos conveniados com a Secult, entre 2008 e 2009, apenas 17 prestaram contas da última parcela e estão em fase de finalização do 
Políticas Culturais em Revista, 2(7), p. 26-45, 2014 - www.politicasculturaisemrevista.ufba.br convênio $^{8}$. Ou seja, o projeto que deveria ter duração de três anos, na prática, dura mais de seis.

Observa-se, neste aspecto, que os problemas são semelhantes aos vivenciados pelo MinC e sua rede de projetos, conforme a pesquisa do IPEA (2010, p. 37):

Os maiores problemas apontados se referem à questão dos repasses de
recursos, que sofrem descontinuidades e atrasos freqüentes por razões
diversas, entre as quais contingenciamentos, condicionamento a complicada
prestação de contas, e mudanças constantes das regras que definem quais
gastos podem ser realizados. Da parte da Secult, houve tentativas de reduzir tais problemas, por meio de realização de oficinas de revisão de Planos de Trabalho; atendimento contínuo para esclarecimento de dúvidas sobre o uso do recurso; contratação de pareceristas externos para participar da análise das prestações de contas, no intuito de agilizar o trabalho etc. Entretanto, tais ações se mostraram insuficientes.

Tudo indica que a incapacidade das entidades de cumprir as exigências do Estado, e todos os problemas observados na gestão do Projeto "[...] denunciam algo mais profundo: o imenso fosso entre o estado nacional realmente existente e as necessidades, interesses e demandas dos dominados" (RUBIM, 2009, p. 21).

[...]. O Programa Cultura Viva/Projeto Pontos de Cultura, ao fazer interagir o estado com tais modalidades culturais e seus atores, expõe de modo contundente este caráter excludente e denuncia a grave inadequação existente no país entre estado e sociedade. (RUBIM, 2009, p. 21)

O que está por trás desse cenário, portanto, é a distância que existe entre Estado e grupos sociais que não fazem (ou não faziam) parte de sua área de atuação, e os Pontos estão situados justamente nessa zona.

Nesse sentido, um passo importante para o fortalecimento do Cultura Viva e do Ponto de Cultura é a instituição da Lei $n^{\circ} 13.018 / 14$ (Lei Cultura Viva), que tem como principal objetivo a ampliação do acesso da população aos seus direitos culturais, mediante o fortalecimento das ações de grupos culturais já atuantes na comunidade ${ }^{9}$ (BRASIL, 2014).

Dois aspectos dessa Lei despertam a atenção para os temas relacionados à gestão e à estadualização. Em relação ao primeiro, podemos ressaltar: alteração da duração do projeto (não mais fixo em três anos); indicação de renovação de convênio dos Pontos e Pontões; e a

\footnotetext{
${ }^{8}$ Informação obtida na Sudecult em novembro de 2014.

${ }^{9}$ Disponível em: <http://www.cultura.gov.br/cultura-viva1>. Acesso em: 10 nov. 2014.
} 
Políticas Culturais em Revista, 2(7), p. 26-45, 2014 - www.politicasculturaisemrevista.ufba.br

previsão de que as normas relativas à prestação de contas passarão a ser definidas em regulamento próprio, conforme prevê o $A r t 7^{\circ}, \S 3^{\circ}$. Em relação à estadualização, o Art. $8^{\circ}$ estabelece que "A Política Nacional de Cultura Viva é de responsabilidade do Ministério da Cultura, dos Estados, do Distrito Federal e dos Municípios integrantes do Sistema Nacional de Cultura" (BRASIL, 2014, p. 4). E o seu $\S 2^{\circ}$ indica que:

O Ministério da Cultura disporá sobre os critérios gerais de distribuição e destinação dos recursos, com atenção especial aos custos diferenciados das regiões do País, e os procedimentos operacionais para elaboração e divulgação das prestações de contas, que serão simplificadas e essencialmente fundamentadas nos resultados previstos nos editais. (BRASIL, 2014, p. 4)

Isso significa que o Programa passará por reestruturações importantes e que manterá, em caráter definitivo, a sua relação com os entes subnacionais.

\section{Considerações finais}

O Programa Cultura Viva e, especialmente, o Projeto Ponto de Cultura é um marco na política cultural brasileira. Sua importância pôde ser recém-observada, com a publicação da Lei Cultura Viva, que o institucionaliza na perspectiva de garantir a sua continuidade.

A importância que o Programa possui já havia sido destacada, por exemplo, com a sua inserção como piloto de processos de descentralização conduzidos pelo MinC. O Mais Cultura, responsável por estruturar e viabilizar tal dinâmica, utilizou vários projetos que integravam o Cultura Viva, dentre eles o Ponto de Cultura.

A expectativa de fortalecer o pacto federativo por meio da estadualização desse Projeto trouxe consequências interessantes. A Secretaria de Cultura do Estado Bahia, um dos órgãos que o implementaram, experimentou novas ações vinculadas ao Projeto. Além disso, buscou melhorias na sua gestão, intensificando, por exemplo, a comunicação com os Pontos. Apesar disso, observou-se que os problemas vivenciados pelas entidades conveniadas diretamente com o MinC também atingiram aquelas conveniadas com a Secult. Nesse sentido, a estadualização não solucionou os problemas experimentados na esfera federal. Pelo contrário, reproduziu os impasses.

Outra questão que surge nesse cenário é o modelo de descentralização de políticas culturais do MinC. Com o Sistema Nacional de Cultura em fase de implementação, é um bom exercício analisar casos como a estadualização do Cultura Viva. Afinal, com o Mais Cultura, observouse que o Ministério optou por reproduzir seus programas e projetos de Norte a Sul do Brasil, 
Políticas Culturais em Revista, 2(7), p. 26-45, 2014 - www.politicasculturaisemrevista.ufba.br sem que Estados e municípios pudessem participar de processos de concepção e elaboração. Considerando a diversidade do Brasil, tanto no aspecto cultural, quanto territorial, e a proposta do SNC de ser "organizado em regime de colaboração, de forma horizontal, aberta, descentralizada e participativa", conforme Art. 216-A da Constituição Federal, seria importante pensar em ações que favorecessem e se adequassem melhor a essa diversidade.

Por fim, a análise da estadualização do Projeto Ponto de Cultura revelou o quão inadequado é a base de relação entre Estado e sociedade civil no Brasil. Colocar essa questão em discussão é fundamental na perspectiva do SNC de efetivar os direitos culturais garantidos a todos os cidadãos brasileiros. 


\section{Referências}

ARRETCHE, M. Mitos da descentralização: mais democracia e eficiência nas políticas públicas? Revista Brasileira de Ciências Sociais, São Paulo, n. 31, 1996. Disponível em: $<$ http://www.anpocs.org.br/portal/publicacoes/rbcs_00_31/rbcs31_03.htm>. Acesso em: 10 nov. 2010.

BAHIA. Governo do Estado. Secretaria de Cultura da Bahia. Edital de Seleção nº 01 de 26 de março de 2008. Seleciona instituições da sociedade civil sem fins lucrativos para atuarem como Pontos de Cultura na Bahia. Diário Oficial do Estado, 27 mar. 2008.

Procuradoria Geral do Estado. Parecer N. PGE-SECULT-Z-396/2008. Análise da Procuradoria Geral do Estado da Bahia sobre a aplicabilidade da Lei Estadual 9433/2005 para reger as relações Estado-entidades Pontos de Cultura. Proferido em 5 de jun. 2008.

Secretaria Estadual de Cultura da Bahia. Relatório final: Programa Jovens Multiplicadores - 2012 a 2014.

BRASIL. Constituição (1988). Constituição da República Federativa do Brasil. Brasília, DF: Senado, 1988.

Decreto 6.226, de 4 de outubro de 2007. Institui o Programa Mais Cultura. Portal da legislação: Leis ordinárias. Disponível em:

$<$ http://www.planalto.gov.br/ccivil_03/_Ato2007-2010/2007/Decreto/D6226.htm > . Acesso em: 10 out. 2010.

Lei 13.018, de 22 de julho de 2014. Institui a Política Nacional de Cultura Viva e dá outras providências. Portal da legislação: Leis ordinárias. Disponível em: $<$ http://www.planalto.gov.br/ccivil_03/_Ato2011-2014/2014/Lei/L13018.htm>. Acesso em: 20 nov. 2014.

Presidência da República. Programa de Aceleração do Crescimento. 2010. Disponível em: <http://www.brasil.gov.br/pac/o-pac/>. Acesso em: 05 mai. 2010.

Ministério da Cultura. Extrato de Convênio 00427/2007. Publica a assinatura do convênio entre o Ministério da Cultura e a Secretaria de Cultura da Bahia para implantação da Rede de Pontos de Cultura da Bahia. Diário Oficial da União, Poder Executivo, Brasília, DF, 14 de janeiro de 2008.

Ministério da Cultura. Convênio de Cooperação No 427/2007 celebrado entre o Ministério da Cultura e a Secretaria de Cultura da Bahia para implantação da Rede de Pontos de Cultura da Bahia. 
Acordo de Cooperação entre o Ministério da Cultura e os entes subnacionais para implementar o Programa Mais Cultura. Disponível em: $<$ http://mais.cultura.gov.br/>. Acesso em: 5 nov. 2010.

CALABRE, L. Políticas Culturais no governo Lula: um estudo do Programa Mais Cultura. In: ENCONTRO DE ESTUDOS MULTIDISCIPLINARES EM CULTURA, 6., 2010, Salvador. Anais... Salvador: Enecult, 2010. Disponível em:

<http://www.cult.ufba.br/wordpress/24370.pdf>. Acesso em: nov. 2014.

Política Cultural em tempos de democracia: a Era Lula. Revista do Instituto de

Estudos Brasileiros, São Paulo, n. 58, p.137-156, 2014.

CANEDO, D. P. Cultura, democracia e participação social: um estudo da II Conferência Estadual de Cultura da Bahia. 2008. 191 f. Dissertação (Mestrado em Cultura e Sociedade) Faculdade de Comunicação, Universidade Federal da Bahia, Salvador, 2008.

CARVALHO, E. F.; LEPIKSON, J. A. PAC e a nova concepção de política econômica do governo Lula. 2007. Disponível em:

$<$ http://www.nec.ufba.br/artigos/Inflacao_Politica_Monetaria_e_Fiscal/2007/2007.02\%20\%20PAC $\% 20 \mathrm{e} \% 20 \mathrm{a} \% 20$ nova\%20concep $\% \mathrm{C} 3 \%$ A7\%C3\%A3o\%20de\%20pol\%C3\%ADtica \%20econ\%C3\%B4mica\%20do\%20governo\%20Lula.pdf $>$. Acesso em: 5 mai. 2010.

FERREIRA, J. Mais Cultura na Bahia - MinC e o Governo da Bahia farão investimento em todo estado nos próximos 3 anos. 2008. Disponível em: <http://www.iteia.org.br/maiscultura-na-bahia/5>. Acesso em: 5 nov. 2014.

GIL, G. Discurso do ministro Gilberto Gil no lançamento do Programa Mais Cultura. Brasília, 4 out. 2007. Disponível em: <http://www.cultura.gov.br/noticias/discursos/index. php?p=30210\&more $=1 \& c=1 \& p b=1>$. Acesso em: 12 jan. 2008.

IPEA. Cultura Viva: avaliação do programa arte educação e cidadania. Brasília, DF: Ipea, 2010.

. Cultura viva: as práticas de pontos e pontões. Brasília, DF: Ipea, 2011.

JACOBI, P. R. Políticas sociais e ampliação da cidadania. Rio de Janeiro: FGV, 2000.

LIMA, D. R. A construção de uma agenda pública para o desenvolvimento local: o caso do Programa Mais Cultura. In: IV ENCONTRO NACIONAL DA ULEPICC-BRASIL, 4., 2012, Rio de Janeiro. Anais... Rio de Janeiro: Ulepicc, 2012. Disponível em:

$<$ http://ulepiccbrasil4.com.br/anais/pdf/gt4/LIMA_a_construcao_de_uma_agenda_publica_pa ra_o_desenvolvimento_local_o_caso_do_programa_mais_cultura.pdf $>$. Acesso em: 5 nov. 2014. 
ROCHA, S. C. Programa Cultura Viva e seu processo de estadualização na Bahia. 2011. 233 f. Dissertação (Mestrado em Cultura e Sociedade) - Faculdade de Comunicação, Universidade Federal da Bahia, Salvador, 2011. Disponível em:

$<$ https://repositorio.ufba.br/ri/bitstream/ri/16299/1/Disserta\%C3\%A7\%C3\%A3o_Sophia\%20 Rocha.pdf $>$. Acesso em: 5 nov. 2014.

RUA, M. G. Análise de políticas públicas: conceitos básicos. In: RUA, M. G.; CARVALHO, M. (Orgs.). O estudo da política: tópicos selecionados. Brasília, DF: Paralelo 15, 1998. Disponível em:

$<$ http://vsites.unb.br/ceam/webceam/nucleos/omni/observa/downloads/pol_publicas.PDF $>$. Acesso em: 15 nov. 2010.

RUBIM, A. Programa Cultura Viva - projeto Pontos de Cultura. In: Seminário Internacional do Programa Cultura Viva: novos mapas conceituais. Brasília, DF: Ministério da Cultura, 2009. p. 21-22.

Albino Rubim [nov. 2014]. Entrevistadores: Lucas Cunha, Maria Garcia e Rebeca Menezes. Bahia Notícias, Salvador, 17 nov. 2014. Disponível em:

$<$ http://www.bahianoticias.com.br/entrevista/385-albino-rubim.html $>$. Acesso em: 18 nov. 2014.

SILVA, F. B. As políticas públicas e suas narrativas: o estranho caso entre o Mais Cultura e o Sistema Nacional de Cultura. Brasília: Ipea, 2011.

TURINO, C. Ponto de Cultura: o Brasil de baixo para cima. São Paulo: Anita Garibaldi, 2009. 